\title{
Estudo da Viabilidade de Bifidobacterium longum em Bebidas Lácteas Probióticas
}

\author{
Luana Sabrine Silva (I), Ana Cláudia Morais Souza (I), Marcelo \\ Morais Maria (I), Annatachi Botelho Jardim (II), Washington \\ Azevedo da Silva (I), Christiano Vieira Pires (I), Marcelo Resende \\ Souza (II), Andréia Marçal da Silva (I) \\ (I) UFSJ - Universidade Federal de São João del-Rei (Rodovia MG 424, Km 47 - Sete Lagoas - \\ MG), (II) UFMG - Universidade Federal de Minas Gerais (Av. Antônio Carlos, 6627 - Pampulha \\ - Belo Horizonte - MG)
}

\section{Resumo}

O desenvolvimento de bebidas lácteas funcionais vem sendo o enfoque das indústrias de leite que almejam ao mesmo tempo aproveitar o soro lácteo (obtendo um produto de maior valor agregado) e diminuir o impacto ambiental. Apesar de pouco explorado, o soro pode ser empregado amplamente na elaboração de produtos lácteos por ainda apresentar uma rica composição nutricional. Sendo assim, o objetivo deste trabalho foi desenvolver uma bebida láctea funcional, com o soro proveniente da manufatura de queijos. Duas bebidas lácteas de sabor chocolate foram formuladas com $40 \%$ (v/v) de soro cada: uma comum e outra probiótica, ambas acondicionadas em garrafas plásticas. No caso da bebida probiótica, após a pasteurização e abaixamento da temperatura para $37^{\circ} \mathrm{C}$, a cultura de Bifidobacterium longum foi adicionada. Análises microbiológicas e físicoquímicas foram feitas, em três repetições, nas bebidas ao longo do tempo de estocagem sob refrigeração $(1,7,14,21$ e 28 dias). As pesquisas de micro-organismos patógenos e de deteriorantes nas bebidas lácteas mostraram resultados em conformidade com os padrões exigidos pela legislação. Não houve diferença $(\mathrm{P}>0,05)$ em relação à contagem de $\mathrm{B}$. longum entre os tempos de estocagem da bebida láctea probiótica. Os níveis populacionais mantiveram-se acima de $10^{6} \mathrm{UFC} / \mathrm{mL}$, durante todo o

\footnotetext{
Referência:

Luana Sabrine Silva, Ana Cláudia Morais Souza, Marcelo Morais Maria, Annatachi Botelho Jardim, Washington Azevedo da Silva, Christiano Vieira Pires, Marcelo Resende Souza, Andréia Marçal da Silva. Estudo da Viabilidade de Bifidobacterium Longum em Bebidas Lácteas Probióticas. In: Anais do 12 Congresso Latinoamericano de Microbiologia e Higiene de Alimentos - MICROAL 2014 [= Blucher Food Science Proceedings, num.1, vol.1]. São Paulo: Editora Blucher, 2014.

DOI 10.5151/foodsci-microal-155
} 
tempo de armazenamento sob refrigeração; porém, as mesmas se deterioraram antes do final da vida de prateleira. As bebidas lácteas apresentaram teores médios de proteína conforme o especificado pela legislação, sendo que a bebida láctea probiótica teve um teor percentual protéico médio maior $(2,88 \%)$. A partir do $14^{\circ}$ dia observou-se queda dos valores de $\mathrm{pH}$ nas duas bebidas lácteas, o que reflete crescimento microbiano ao longo do período de estocagem. As bebidas lácteas possuíram alegação funcional durante todo o período de armazenamento, estando em conformidade com a legislação vigente. Como as embalagens plásticas possuem diferentes taxas de permeabilidade ao oxigênio, a avaliação em outros tipos pode ser promissora, influenciando positivamente a estabilidade microbiológica.

Palavras-Chave: alimentos funcionais, bebida láctea, Bifidobacterium longum, probióticos

Agência de Fomento: FAPEMIG 